\title{
Stirling engines - the state of technology development and computational models
}

ARTICLE INFO

Received: 12 August 2021

Revised: 31 August 2021

Accepted: 8 September 2021

Available online: 13 September 2021
Stirling engines represent a technologically important solution in combined heat and power systems. Their use enables the achievement of over 90 percent efficiency in the management of the primary energy source with a very high durability of the device, mainly due to the lack of contact of the working gas with external factors and a very small number of mechanical components. The use of a Stirling engine may be equally important when applying renewable energy sources or waste heat from other processes. The first part of the work presents an overview of available commercial Stirling engine solutions. The second part of the work presents an overview of numerical models of Stirling engine operation, which enable the correct selection of the main geometrical features of the devices and the improvement of the structure in order to maximize efficiency or power.

Key words: Stirling engines, numerical models, commercial designs, low temperature sources, renewable energy sources

This is an open access article under the CC BY license (http://creativecommons.org/licenses/BY/4.0/)

\section{Introduction}

Stirling engines are one of the possible technological solutions enabling the management of the renewable and waste energy sources [10]. Currently, their main commercial application, however, is the production of heat and electricity from conventional energy sources, such as natural gas, diesel oil $[8,11,20]$. One of the most important technical problems related to the use of Stirling engines to generate electricity from low-temperature energy sources is the need to meet two basic countercurrent requirements, minimizing the dead volume associated with transporting the working gas between the compression and expansion spaces, and maximizing the heat exchange surface to provide the right amount of heat to the system with a lowtemperature difference $[18,21,25]$. The optimization of the Stirling engine design requires very precise mapping of the influence of the above-mentioned design features on the efficiency and power of the system. For this purpose, computational models with varying degrees of details and accuracy are used. The paper presents an overview of the technology development of these structures.

\section{Preview of commercial solutions}

Stirling engine is powered from external source (an external chamber engine). This fact allows using heat for two simultaneous processes - heating and electricity production. The ability of supplying from the technological process as well (i.e. chemical or metallurgy industries) leads to reduce emission of carbon dioxide and consumption of fossil fuels. The Stirling engine is able to support process of electricity production with solar energy. Commercial systems aim at only electricity production or cogeneration working. These systems might be supplied by solid fuels, gas fuels and liquid fuels. Some commercial constructions have been presented below (Table 1).

Company Genoa offers engines in two variants $[11,12]$. In the first configuration engines have one cylinder (configuration beta) and reach $1 \mathrm{~kW}$ (Fig. 1).The second configuration is equipped with two cylinders (configuration alpha) of power $3 \mathrm{~kW}$ (Fig. 2). Nitrogen is a working medi$\mathrm{um}$ in both engines. Biomass and natural gas is a source of heat. These engines require $700^{\circ} \mathrm{C}$ to start up, the heat source should have at least $850^{\circ} \mathrm{C}$

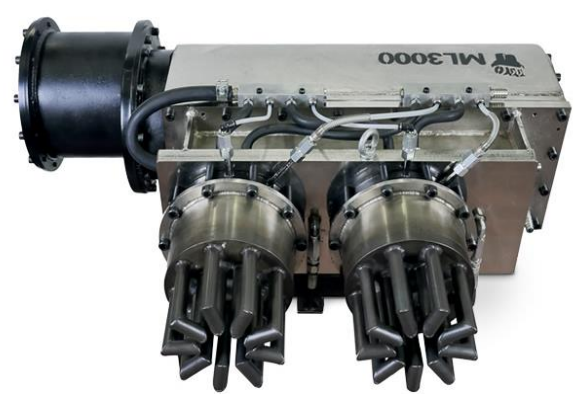

Fig. 1. Two-cylinder Stirling engine Genoa, ML3000, power 3 kWe [13]

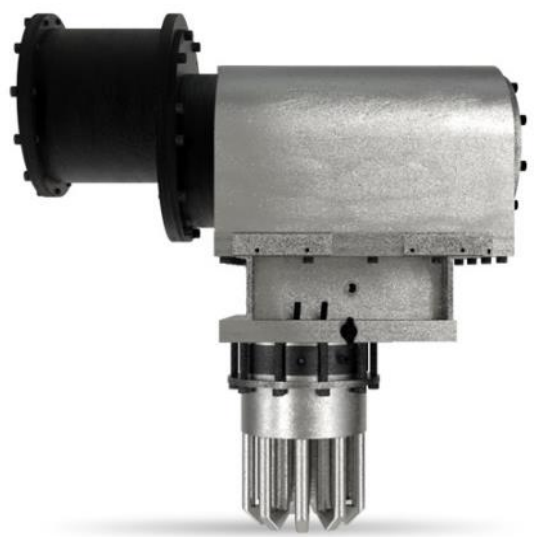

Fig. 2. One-cylinder Stirling engine Genoa ML1000, power 1 kWe [19]

Microgen products are based on one cylinder beta type Stirling engine. Available is setup with $1 \mathrm{~kW}$ and $2 \mathrm{~kW}$ electric power and heat might be generated in an external combustion chamber produced by burning natural gas or solid fuels. These engines belong to group free piston Stirling engines. Linear generator converts motion of piston on electric energy. This engine starts from about $180^{\circ} \mathrm{C}$ (working medium temperature). In Fig. 3 a view of Microgen Stirling engine has been presented. 


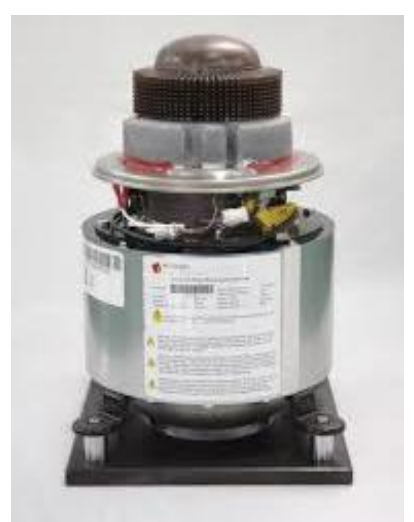

Fig. 3. One-cylinder Microgen, power $1 \mathrm{kWe}$ [5]

System of Inspirit Company includes generation of heat and electricity. In this solution the beta Stirling engine with free piston has been used. Overall efficiency equals to $92 \%$ including $16 \%$ of electric efficiency. In this case the heat of source is limited to natural gas. Version 3.1 is offered on the market. Previous versions of the engine generating lower power, i.e. Inspirit Charger 2.0 1-2 kWe and 5-10 kWt and Charger $3.01-3 \mathrm{kWe}$ and 5-15 kWt. The last revision 3.1 offers up to $6.4 \mathrm{kWe}$ and $15 \mathrm{kWt}$. In Fig. 4 Stirling engine of Inspirit (view on heater) has been presented.

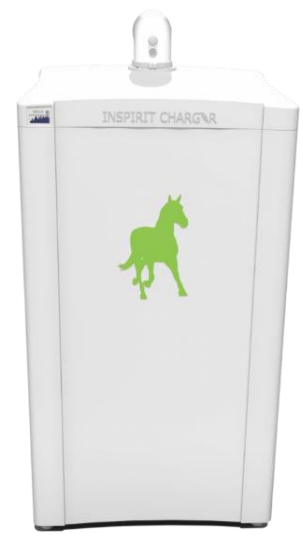

Fig. 4. CHP Inspirit Stirling engine, power $1 \mathrm{kWe}[8]$

WhisperGen is distinguished by a lower electric power. In comparison with the engines previously presented, product of WhisperGen is prepared for working on land and sea. WhisperGen PPS 16 reaches $750 \mathrm{~W}$ of electric power and 5 $\mathrm{kW}$ of thermal power. The upper limit of the heat source is set to $550^{\circ} \mathrm{C}$. In Fig. 5 the WhisperGen PPS 16 has been presented.

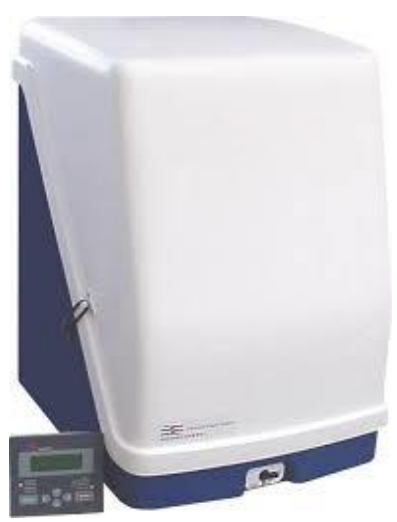

Fig. 5. Stirling engine Whispergen PPS16, power 0.75 kWe [28]

Engines of Powergen series are based on the beta free piston Stirling engines with linear generators also in two variants of power, respectively $1.2 \mathrm{kWe}$ and $5.65 \mathrm{kWe}$ (Fig. 6). Produced heat exceeds 2 to 3 times electricity production. Electric efficiency is estimated on $30 \%$ (the highest value for analyzed construction). The working gas temperature in the heater can operate in the range $400-800^{\circ} \mathrm{C}$. Engines of Powergen Company use helium as a working gas.

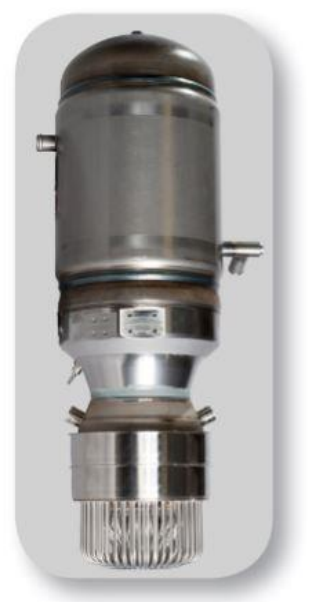

Fig. 6. Stirling engine Qnery PowergGen 1200/5650, power $1.2 \mathrm{kWe} / 5.65$ $\mathrm{kWe}[15,16]$

In the Table 1 has been presented engines specification of Genoa and Microgen. In the Table 2 has been presented engines specification of WhisperGen, Qnergy and Inspirit Charger.

Table 1. Technical specification of Genoa Stirling and Microgen

\begin{tabular}{|c|c|c|c|c|c|}
\hline Parameter & Unit & Genoa ML3000 & Genoa ML1000 & Microgen $1 \mathrm{~kW}$ & Microgen $2 \mathrm{~kW}$ \\
\hline Electric power & $\mathrm{kWe}$ & 3.3 & 1.1 & 1.05 & 2 \\
\hline Thermal power & $\mathrm{kWt}$ & 18.6 & 10 & 4 & 8 \\
\hline Electric efficiency & $\%$ & 14 & 14 & $15.5-23$ & $15.5-23$ \\
\hline Power supply & - & Gas or biomass & Gas or biomass & $\begin{array}{l}\text { Pellet, briquette, wood, } \\
\text { natural gas or heating oil }\end{array}$ & $\begin{array}{l}\text { Pellet, briquette, wood, } \\
\text { natural gas or heating oil }\end{array}$ \\
\hline Working medium & - & Nitrogen (air) & Nitrogen (air) & Air & Air \\
\hline Working temperature (hot side) & ${ }^{\circ} \mathrm{C}$ & $850-900$ & $850-900$ & $180-525$ & $180-525$ \\
\hline Cooling medium & - & Water & Water & Air & Air \\
\hline $\begin{array}{l}\text { Working temperature inlet/outlet } \\
\text { (cold side) }\end{array}$ & ${ }^{\circ} \mathrm{C}$ & $15 / 60$ & $15 / 40$ & $\begin{array}{l}\text { Min. 6/max 70; } \\
\text { nominal } 30\end{array}$ & $\begin{array}{l}\text { Min. 6/max 70; } \\
\text { nominal } 30\end{array}$ \\
\hline Cooling medium flow & $\mathrm{dm}^{3} / \mathrm{min}$ & 6.5 & 6.5 & Nominal 8 (minimum 7) & Nominal 8 (minimum 7) \\
\hline
\end{tabular}


Stirling engines - the state of technology development and computational models

Table 2. Technical specification of WhisperGen, Qnergy and Inspirit

\begin{tabular}{|c|c|c|c|c|c|}
\hline Parameter & Unit & WhispeGen PPS16 & Qnergy PowerGen 1200 & $\begin{array}{l}\text { Qnergy PowerGen } \\
5650\end{array}$ & Inspirit Charger 3.1 \\
\hline Electric power & $\mathrm{kWe}$ & 0.75 & 1.2 & 5.65 & $1-6.4$ \\
\hline Thermal power & $\mathrm{kWt}$ & 5 & $3-4.5$ & $14-20$ & $5-15$ \\
\hline Electric efficiency & $\%$ & - & 30 & 30 & 16 \\
\hline Power supply & - & $\begin{array}{l}\text { Burning refined paraffin } \\
\text { or diesel oil }\end{array}$ & Natural gas & $\begin{array}{l}\text { Burning natural gas, } \\
\text { LPG, propane }\end{array}$ & Natural gas \\
\hline Working medium & - & Nitrogen & Helium & Helium & - \\
\hline Working temperature (hot side) & ${ }^{\circ} \mathrm{C}$ & Up to 550 & $400-800$ & $400-800$ & - \\
\hline Cooling medium & - & Glycol & - & - & Water \\
\hline $\begin{array}{l}\text { Working temperature inlet/outlet } \\
\text { (cold side) }\end{array}$ & ${ }^{\circ} \mathrm{C}$ & $45 / 70$ & - & - & $60 / 80$ \\
\hline Cooling medium flow & $\mathrm{dm}^{3} / \mathrm{min}$ & - & - & - & - \\
\hline
\end{tabular}

\section{Numerical models of Stirling engine}

\subsection{Isothermal model}

Mathematical model of Stirling engine was shown by Gustav Schmidt in 1871. Two basic assumptions of the model are constant temperature in each selected spaces and sinusoidal changing of volume working gas [1]. A heat included in the working gas is transformed to work. There is no heat transfer between environment and cooler, regenerator and heater. Heat transfer is realized in expansion and compression space. Based on these assumption, the engine works is a constant range of temperatures, the maximum temperature is reached in heater and expansion space, whereas the minimum temperature is observed in cooler and workspace called compression space. Those assumption cannot be met in a real engine because of the expected isothermal processing of the cycle, which requires infinity heat transfer surface in the heat exchangers [3].

It can mark out five work spaces of the engine: compression space $\mathrm{c}$, cooler $\mathrm{k}$, regenerator $\mathrm{r}$, heater $\mathrm{h}$ and $\mathrm{ex}-$ pansion space e. In Fig. 7 layout of temperature in work spaces was shown.
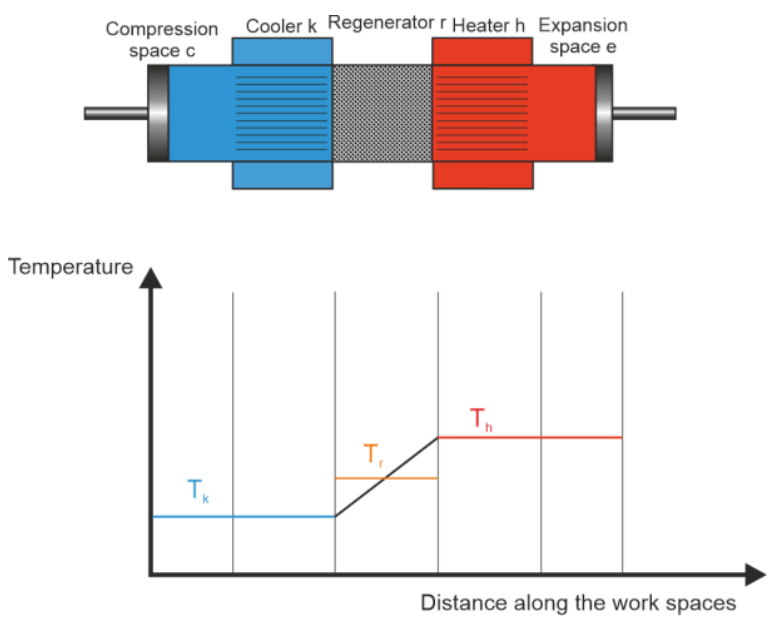

Fig. 7. Temperature profile in workspaces for isothermal model [23]

Assumptions for isothermal model are as follows [23]:

1. The constant gas temperature is over a surface of piston and in heat exchanger i.e. in compression space and in cooler (average temperature of lower heat source) are equal, that is $T_{c}=T_{k}$. . The same rule is obeyed in the expansion space and the heater $T_{e}=T_{h}$.

2. Rotational speed is constant.
3. The total mass of the working gas is constant (no leakage) in accordance with the following equation (1):

$$
\mathrm{M}=\mathrm{m}_{\mathrm{c}}+\mathrm{m}_{\mathrm{k}}+\mathrm{m}_{\mathrm{r}}+\mathrm{m}_{\mathrm{h}}+\mathrm{m}_{\mathrm{e}}
$$

where $\mathrm{M}$ is the total mass of working gas in the system, $\mathrm{m}_{\mathrm{c}}$ is the mass of working gas in the compression space, $\mathrm{m}_{\mathrm{k}}$ is the mass of working gas in the cooler, $\mathrm{m}_{\mathrm{r}}$ is the mass of working gas in the cooler, $\mathrm{m}_{\mathrm{h}}$ is the mass of working gas in the heater and $m_{e}$ is the mass of working gas in the expansion space.

4. Working gas is considered as an ideal gas.

5. The pressure of the working gas is the same in all spaces.

6. Volume change in the working spaces is sinusoidal.

7. Changes in kinetic and potential energy are negligible.

As a result of the usage of the Clapeyron equation, the total mass of gas equals:

$$
\mathrm{M}=\frac{\mathrm{P}}{\mathrm{R}}\left(\frac{\mathrm{V}_{\mathrm{c}}}{\mathrm{T}_{\mathrm{k}}}+\frac{\mathrm{V}_{\mathrm{k}}}{\mathrm{T}_{\mathrm{k}}}+\frac{\mathrm{V}_{\mathrm{r}}}{\mathrm{T}_{\mathrm{r}}}+\frac{\mathrm{V}_{\mathrm{h}}}{\mathrm{T}_{\mathrm{h}}}+\frac{\mathrm{V}_{\mathrm{e}}}{\mathrm{T}_{\mathrm{h}}}\right)
$$

where $\mathrm{P}$ is the working gas pressure, $\mathrm{R}$ is the individual gas constant of working substance, $\mathrm{V}$ is the volume of working gas and $\mathrm{T}$ is the absolute temperature of working gas. After transformation equation (2) the formula of the pressure in the system is defined as:

$$
P=\frac{M R}{\left(\frac{V_{c}}{T_{k}}+\frac{V_{k}}{T_{k}}+\frac{V_{r}}{T_{r}}+\frac{V_{h}}{T_{h}}+\frac{V_{e}}{T_{h}}\right)}
$$

Temperature distribution in the regenerator is described by a linear function. In Fig. 8 the distribution of the temperature was shown. On the basis of the assumption there is no heat losses, the change of temperature is the same during heating and cooling process.

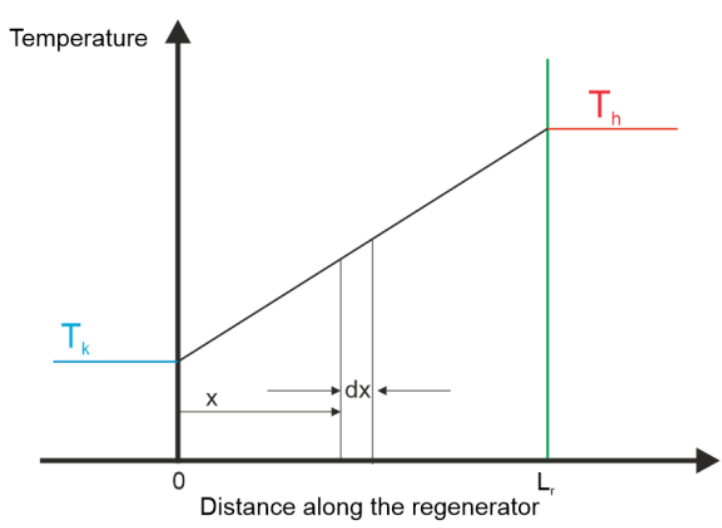

Fig. 8. Temperature distribution in ideal regenerator [24] 
The change of temperature along the regenerator can be therefore defined as follows:

$$
\frac{\mathrm{T}(\mathrm{x})}{\mathrm{x}}=\frac{\mathrm{T}_{\mathrm{h}}-\mathrm{T}_{\mathrm{k}}}{\mathrm{L}_{\mathrm{r}}}+\mathrm{T}_{\mathrm{k}}
$$

where $T(x)$ is the absolute gas temperature away of the inlet and $L_{r}$ is the regenerator length.

By making transformations, we get:

$$
\mathrm{T}(\mathrm{x})=\left(\frac{\mathrm{T}_{\mathrm{h}}-\mathrm{T}_{\mathrm{k}}}{\mathrm{L}_{\mathrm{r}}}\right) \mathrm{x}+\mathrm{T}_{\mathrm{k}}
$$

The mass of gas in the regenerator is determined by the following formula:

$$
\mathrm{m}_{\mathrm{r}}=\int_{0}^{\mathrm{V}_{\mathrm{r}}} \mathrm{gdV} \mathrm{V}_{\mathrm{r}}
$$

where $m_{r}$ is the accumulated mass of gas in the workspace of regenerator, $\varrho$ is the gas density and $\mathrm{V}_{\mathrm{r}}$ is the volume of the regenerator workspace. The formula of gas density is define based on Clapeyron equation as:

$$
\varrho=\frac{\mathrm{RT}}{\mathrm{p}}
$$

Volume of regenerator $\mathrm{V}_{\mathrm{r}}$ is equal:

$$
\mathrm{V}_{\mathrm{r}}=\mathrm{A}_{\mathrm{r}} \mathrm{L}_{\mathrm{r}}
$$

In differential form volume of regenerator equals:

$$
\mathrm{dV}_{\mathrm{r}}=\mathrm{A}_{\mathrm{r}} \mathrm{dx}
$$

Using equations (7)-(9) the final form of form of equation (6) is given by:

$$
\mathrm{m}_{\mathrm{r}}=\frac{\mathrm{V}_{\mathrm{r}} \mathrm{P}}{\mathrm{R}} \int_{0}^{\mathrm{L}_{\mathrm{r}}} \frac{1}{\mathrm{~T}(\mathrm{x}) \mathrm{l}_{\mathrm{r}}} \mathrm{dx}
$$

Subsequently using equation (4) we obtain:

$$
\mathrm{m}_{\mathrm{r}}=\frac{\mathrm{V}_{\mathrm{r}} \mathrm{P}}{\mathrm{R}} \int_{0}^{\mathrm{L}_{\mathrm{r}}} \frac{1}{\left(\mathrm{~T}_{\mathrm{h}}-\mathrm{T}_{\mathrm{k}}\right) \mathrm{x}+\mathrm{T}_{\mathrm{k}} \mathrm{L}_{\mathrm{r}}} \mathrm{dx}
$$

and after integration:

$$
m_{r}=\frac{V_{r} P}{R} \frac{\ln \left(\frac{T_{h}}{T_{k}}\right)}{T_{h}-T_{k}}
$$

or:

$$
\mathrm{m}_{\mathrm{r}}=\frac{\mathrm{V}_{\mathrm{r}} \mathrm{P}}{\mathrm{RT}_{\mathrm{r}}}
$$

Gas pressure is equal in all spaces, this fact allows calculation of mass based on gas volume and temperature. By summarizing formulas (13) and (7) we obtain:

$$
\mathrm{T}_{\mathrm{r}}=\frac{\mathrm{T}_{\mathrm{h}}-\mathrm{T}_{\mathrm{k}}}{\ln \left(\frac{\mathrm{T}_{\mathrm{h}}}{\mathrm{T}_{\mathrm{k}}}\right)}
$$

Work of isothermal process in expansion space equals:

$$
\mathrm{W}_{\mathrm{e}}=\oint \mathrm{PdV}
$$

and respectively work in compression space is calculated by following formula:

$$
\mathrm{W}_{\mathrm{c}}=\oint \mathrm{PdV}
$$

Summarizing generated work in expansion (15) and compression space (16), leads to the total work of engine:

$$
\mathrm{W}=\mathrm{W}_{\mathrm{e}}+\mathrm{W}_{\mathrm{c}}=\oint \mathrm{PdV}_{\mathrm{e}}+\oint \mathrm{PdV}
$$

According to first law of thermodynamics for open system [2]:

$$
\mathrm{dQ}+\left(\mathrm{C}_{\mathrm{p}} \mathrm{T}_{\mathrm{i}} \mathrm{m}_{\mathrm{i}}^{\prime}-\mathrm{C}_{\mathrm{p}} \mathrm{T}_{\mathrm{o}} \mathrm{m}_{\mathrm{o}}^{\prime}\right)=\mathrm{dW}+\mathrm{C}_{\mathrm{v}} \mathrm{d}(\mathrm{mT})
$$

where dQ is the heat transferred from the environment to workspace of cylinder, $\mathrm{C}_{\mathrm{p}}$ is the specific heat by the constant pressure, $\mathrm{T}_{\mathrm{i}}$ is the inlet gas temperature, $\mathrm{m}_{\mathrm{i}}{ }^{\prime}$ is the inlet gas mass, $T_{o}$ is the outlet gas temperature, $m_{o}{ }^{\prime}$ is the outlet gas mass, $\mathrm{dW}$ is the work transferred into the environment and $\mathrm{C}_{\mathrm{v}}$ is the specific heat by the constant volume. In the Fig. 9 the scheme of the cylinder workspace was shown.

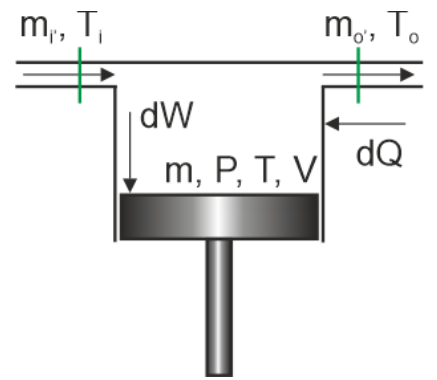

Fig. 9. Scheme of the cylinder workspace $[7,23]$

Isothermal model is leading to simplification of formula (18), because the inlet temperature and the outlet temperature are equal $\left(\mathrm{T}_{\mathrm{i}}=\mathrm{T}_{\mathrm{o}}\right)$. The formula describing difference between the inlet mass $\left(\mathrm{m}_{\mathrm{i}}\right)$ and the outlet mass $\left(\mathrm{m}_{\mathrm{o}}\right)$ is replaced by the parameter $\mathrm{dm}$. Finally it can be described as:

$$
\mathrm{dQ}+\mathrm{C}_{\mathrm{p}} \mathrm{Tdm}=\mathrm{dW}+\mathrm{C}_{\mathrm{v}} \mathrm{Tdm}
$$

Correlation between $c_{p}$ and $c_{v}$ is described as $c_{P}=c_{v}+$ $\mathrm{R}$, which reduces formula (19) to the form:

$$
\mathrm{dQ}=\mathrm{dW}+\mathrm{RTdm}
$$

Amount of the heat transferred into gas working during engine cycle equals integer dQ (20). After integration, the following equations are obtained:

$$
\mathrm{Q}_{\mathrm{c}}=\mathrm{W}_{\mathrm{c}}, \mathrm{Q}_{\mathrm{e}}=\mathrm{W}_{\mathrm{e}}, \mathrm{Q}_{\mathrm{k}}=0, \mathrm{Q}_{\mathrm{h}}=0, \mathrm{Q}_{\mathrm{r}}=0
$$

where $Q_{c}$ is the heat generated during gas compression, $W_{c}$ is the work of compression process, $\mathrm{Q}_{\mathrm{e}}$ is the heat generated during gas expansion, $\mathrm{W}_{\mathrm{e}}$ is the work generated during gas expansion, $\mathrm{Q}_{\mathrm{k}}$ is the heat derived from cooler into environment, $Q_{h}$ is the heat rejected from environment, $Q_{r}$ is the heat losses in regenerator.

The following conclusions can be drawn from the above considerations:

1. The heat exchange is processed only in compression and expansion space.

2. There is no heat losses in the regenerator.

3 . In the heater and the cooler there is no heat transfer.

\subsection{Adiabatic model}

The novel approach in the field of modelling Stirling engine was caused by the adiabatic model developed by Finkelstein [26]. From the point of view of modelling process - compression and expansion cause a significant change. These processes are described by an adiabatic model. The heat transfer into cooler and heater is modelled by the isothermal model. Calculated efficiency based on the isothermal model is higher by about $20-30 \%$ in comparison to adiabatic model [9]. 
Isreaeli Urieli and Dave Berchowitz [26] developed quasi static model of ideal Stirling engine with adiabatic expansion and compression. The assumptions of model are as follows:

1. All processes are realized in a steady state.

2. The rotational speed is constant.

3. The working gas is treated as an ideal gas.

4. Process of compression and expansion are conducted without the heat transfer with the environment.

5. Instantaneous pressure in expansion and compression space is equal.

6. Temperature of gas in the cooler and heater is constant.

7. The change of temperature in regenerator is linear.

8. Kinetic and potential energy is negligible.

9. Heat transfer takes place only in the cooler and heater.

10. Total gas mass in the system is constant.

11. Heat loss as the result of flow between workspaces (compression and expansion) and also heat loss into the environment is negligible.

12. There is no gas leakage.

Split of workspaces was shown in Fig. 10, between workspaces implemented four domains (boundary areas): compression space-cooler ck, cooler-regenerator kr, regenerator-heater rh and heater-expansion space he.

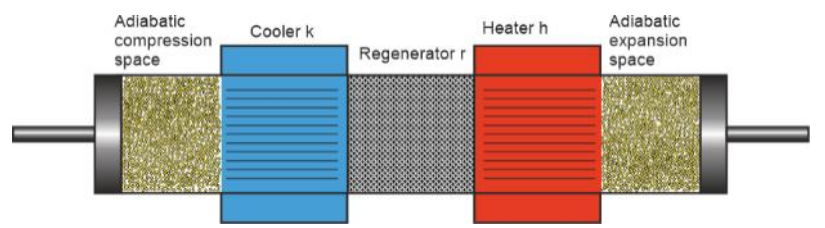

Fig. 10. Scheme of workspaces for adiabatic model [22]

Temperature profile in workspaces with split on domains was presented in Fig. 11.
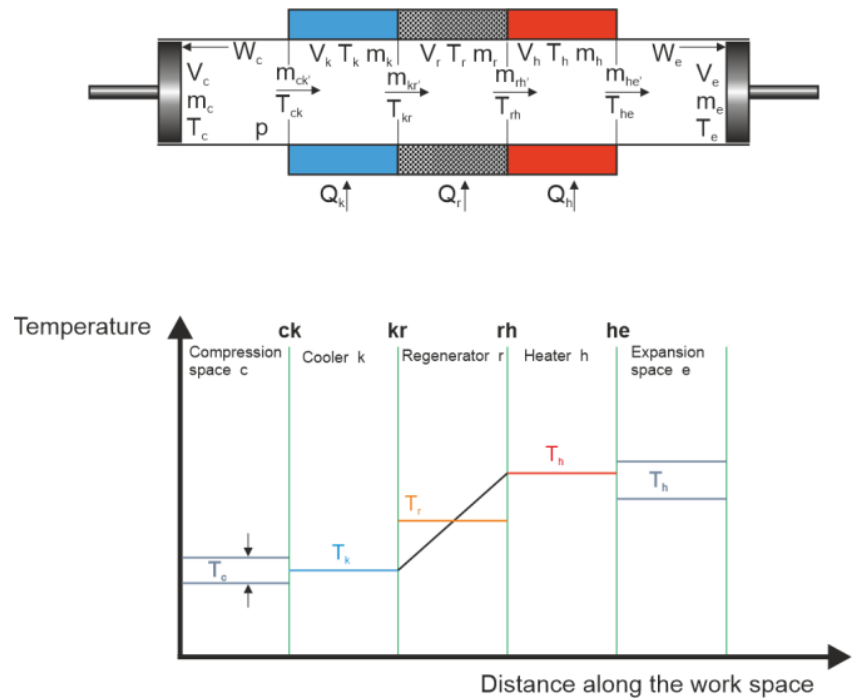

Fig. 11. Temperature profile in workspaces for adiabatic model [22]

The values of temperature on the domain is conditioned by flow direction. Mass flow rate flowing through the domain ck equals $m_{c k}$ '. Positive mass flow rate means gas flow to expansion space, whereas negative is correlated with flow in opposite direction. The value of temperature is determined by direction flow with following equations (21)-(24) [3]:

$$
\begin{aligned}
\mathrm{T}_{\mathrm{ck}} & =\left\{\begin{array}{l}
\mathrm{T}_{\mathrm{c}} \text { for } \dot{\mathrm{m}}_{\mathrm{ck}}>0 \\
\mathrm{~T}_{\mathrm{k}} \text { for } \dot{\mathrm{m}}_{\mathrm{ck}}<0
\end{array}\right. \\
\mathrm{T}_{\mathrm{kr}} & =\left\{\begin{array}{l}
\mathrm{T}_{\mathrm{k}} \text { for } \dot{\mathrm{m}}_{\mathrm{kr}}>0 \\
\mathrm{~T}_{\mathrm{r}} \text { for } \dot{\mathrm{m}}_{\mathrm{kr}}<0
\end{array}\right. \\
\mathrm{T}_{\mathrm{rh}} & =\left\{\begin{array}{l}
\mathrm{T}_{\mathrm{r}} \text { for } \dot{\mathrm{m}}_{\mathrm{rh}}>0 \\
\mathrm{~T}_{\mathrm{h}} \text { for } \dot{\mathrm{m}}_{\mathrm{rh}}<0
\end{array}\right. \\
\mathrm{T}_{\mathrm{he}} & =\left\{\begin{array}{l}
\mathrm{T}_{\mathrm{h}} \text { for } \dot{\mathrm{m}}_{\mathrm{he}}>0 \\
\mathrm{~T}_{\mathrm{e}} \text { for } \dot{\mathrm{m}}_{\mathrm{he}}<0
\end{array}\right.
\end{aligned}
$$

where $T_{c k}$ is the gas temperature, $m_{c k}$ is the mass of working gas on the edge compression space and cooler. In the adiabatic model gas mass is constant (similar isothermal model):

$$
\mathrm{M}=\mathrm{m}_{\mathrm{c}}+\mathrm{m}_{\mathrm{k}}+\mathrm{m}_{\mathrm{r}}+\mathrm{m}_{\mathrm{h}}+\mathrm{m}_{\mathrm{e}}
$$

Working substance is considered as an ideal gas, according to Clapeyron equation in each compartment relationship with thermodynamical parameters are defined:

$$
\mathrm{PV}=\mathrm{mRT}
$$

After differentiating Clapeyron equation (26) has taken the following form:

$$
\frac{\mathrm{dP}}{\mathrm{p}}+\frac{\mathrm{dV}}{\mathrm{V}}=\frac{\mathrm{dm}}{\mathrm{m}}+\frac{\mathrm{dT}}{\mathrm{T}}
$$

Mass balance of system is written as:

$$
d m_{c}+d m_{k}+d m_{r}+d m_{h}+d m_{e}=0
$$

Total gas mass equals:

$$
M=\frac{P}{R}\left(\frac{V_{c}}{T_{k}}+\frac{V_{k}}{T_{k}}+\frac{V_{r}}{T_{r}}+\frac{V_{h}}{T_{h}}+\frac{V_{e}}{T_{h}}\right)
$$

Transforming formula (29), is the following formula has been obtained:

$$
P=\frac{M R}{\left(\frac{V_{c}}{T_{k}}+\frac{V_{k}}{T_{k}}+\frac{V_{r}}{T_{r}}+\frac{V_{h}}{T_{h}}+\frac{V_{e}}{T_{h}}\right)}
$$

Temperature and volume is constant in the heat exchangers (cooler, regenerator and heat) and therefore the formula (27) is reduced to:

$$
\left.\frac{\mathrm{dm}}{\mathrm{m}}\right|_{\mathrm{k}, \mathrm{r}, \mathrm{h}}=\left.\frac{\mathrm{dP}}{\mathrm{P}}\right|_{\mathrm{k}, \mathrm{r}, \mathrm{h}}
$$

Ideal gas equation in differential form is written as:

$$
\mathrm{dm}=\mathrm{dP} \frac{\mathrm{v}}{\mathrm{RT}}
$$

After substitution (31) in equation (28) mass balance equals:

$$
d m_{c}+d m_{e}+d P\left(\frac{m_{k}}{p}+\frac{m_{r}}{p}+\frac{m_{h}}{p}\right)=0
$$

Modification equation (33) by substitution of Clapyeron equation leads to notation:

$$
\mathrm{dm}_{\mathrm{c}}+\mathrm{dm}_{\mathrm{e}}+\frac{\mathrm{dP}}{\mathrm{R}}\left(\frac{\mathrm{V}_{\mathrm{k}}}{\mathrm{T}_{\mathrm{k}}}+\frac{\mathrm{V}_{\mathrm{r}}}{\mathrm{T}_{\mathrm{r}}}+\frac{\mathrm{V}_{\mathrm{h}}}{\mathrm{T}_{\mathrm{h}}}\right)=0
$$

Separated section of analyzed spaces (compression space and cooler) was presented in Fig. 12. 


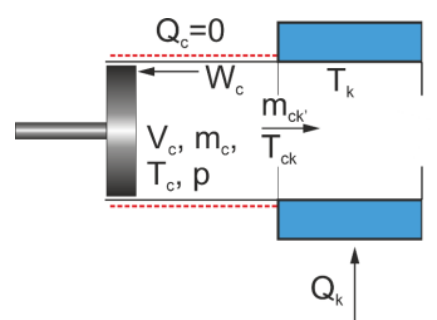

Fig. 12. Scheme of adiabatic compression space and cooler [22]

Compression space is insulated to environment and hence - form of change of internal energy took place only for work. In energy balance for compression space piece of equation related with gas flow in direction cooler occurred [6].

$$
-\mathrm{C}_{\mathrm{p}} \mathrm{T}_{\mathrm{ck}} \dot{\mathrm{m}}_{\mathrm{ck}}=\mathrm{PdV}_{\mathrm{c}}+\mathrm{C}_{\mathrm{V}} \mathrm{d}\left(\mathrm{T}_{\mathrm{c}} \mathrm{m}_{\mathrm{c}}\right)
$$

The gas flow is realized from compression space to cooler thus expression (35) changed their form:

$$
\mathrm{C}_{\mathrm{p}} \mathrm{T}_{\mathrm{ck}} \mathrm{m}_{\mathrm{c}}=\mathrm{PdV}_{\mathrm{c}}+\mathrm{C}_{\mathrm{V}} \mathrm{d}\left(\mathrm{T}_{\mathrm{c}} \mathrm{m}_{\mathrm{c}}\right)
$$

Using assumptions about ideal gas, relationship between specific heat by constant pressure and specific heat by constant volume is related with individual gas constant in next form [19]:

$$
\begin{gathered}
R=C_{p}-C_{V} \\
\kappa=\frac{C_{p}}{C_{V}}
\end{gathered}
$$

where $\kappa$ is the heat capacity ratio. Accumulated gas mass into compression space equals:

$$
\mathrm{dm}_{\mathrm{c}}=\frac{\mathrm{PdV}_{\mathrm{c}}+\frac{\mathrm{V}_{\mathrm{c}} \mathrm{dP}}{\kappa}}{\mathrm{RT}_{\mathrm{ck}}}
$$

and in expansion space:

$$
\mathrm{dm}_{\mathrm{e}}=\frac{\mathrm{PdV}_{\mathrm{e}}+\frac{\mathrm{V}_{\mathrm{e}} \mathrm{dP}}{\kappa}}{\mathrm{RT}_{\mathrm{he}}}
$$

Combining dependencies (37)-(40) a differential equation is obtained describing pressure in system:

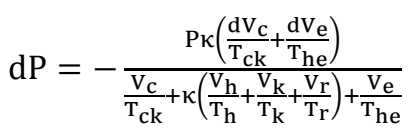

Determining equation of change of pressure (41) creates a system of nonlinear differential equations including parameters for compression space i.e. $\mathrm{T}_{\mathrm{c}}, \mathrm{m}_{\mathrm{c}}$ and expansion $\mathrm{T}_{\mathrm{e}}, \mathrm{m}_{\mathrm{e}}$. Determination of pressure and mass allows gathering other parameters, volumes in workspaces $\mathrm{dV}_{\mathrm{c}}, \mathrm{dV}_{\mathrm{k}}, \mathrm{dV}_{\mathrm{h}}$ and $\mathrm{dV}_{\mathrm{e}}$ which are marked based on kinematic equations. Equation of state gas form compression space has got the following form:

$$
\mathrm{T}_{\mathrm{c}}=\frac{\mathrm{PV}_{\mathrm{c}}}{\mathrm{m}_{\mathrm{c}} \mathrm{R}}
$$

After differentiating state equation (33) equals:

$$
\mathrm{dT}_{\mathrm{c}}=\frac{\mathrm{V}_{\mathrm{c}}}{\mathrm{m}_{\mathrm{c}} \mathrm{R}} \mathrm{dP}+\frac{\mathrm{P}}{\mathrm{m}_{\mathrm{c}} \mathrm{R}} \mathrm{dV}_{\mathrm{c}}-\frac{\mathrm{PV}_{\mathrm{c}}}{\mathrm{R}} \frac{1}{\mathrm{~m}_{\mathrm{c}}^{2}} \mathrm{dm}_{\mathrm{c}}
$$

hence:

$$
\mathrm{dT}_{\mathrm{c}}=\frac{\mathrm{T}_{\mathrm{c}}}{\mathrm{p}} \mathrm{dP}+\frac{\mathrm{T}_{\mathrm{c}}}{\mathrm{V}_{\mathrm{c}}} \mathrm{dV_{c }}-\frac{\mathrm{T}_{\mathrm{c}}}{\mathrm{m}_{\mathrm{c}}} \mathrm{dm}_{\mathrm{c}}
$$

Final form equation of determining temperature in compression space:

$$
\mathrm{dT}_{\mathrm{c}}=\mathrm{T}_{\mathrm{c}}\left(\frac{\mathrm{dP}}{\mathrm{p}}+\frac{\mathrm{dV}_{\mathrm{c}}}{\mathrm{V}_{\mathrm{c}}}-\frac{\mathrm{dm}_{\mathrm{c}}}{\mathrm{m}_{\mathrm{c}}}\right)
$$

In compression space gas temperature is obtained by formula:

$$
\mathrm{dT}_{\mathrm{e}}=\mathrm{T}_{\mathrm{e}}\left(\frac{\mathrm{dP}}{\mathrm{p}}+\frac{\mathrm{dv}_{\mathrm{e}}}{\mathrm{V}_{\mathrm{c}}}-\frac{\mathrm{dm}_{\mathrm{e}}}{\mathrm{m}_{\mathrm{e}}}\right)
$$

Using the energy balance equation for heat exchangers (constant temperature and volume of working gas) and equation state of an ideal gas (26), equation energy balance is written as:

$$
\mathrm{dQ}+\left(\mathrm{C}_{\mathrm{p}} \mathrm{T}_{\mathrm{i}} \mathrm{m}_{\mathrm{i}}^{\prime}-\mathrm{C}_{\mathrm{p}} \mathrm{T}_{\mathrm{o}} \mathrm{m}_{\mathrm{o}}^{\prime}\right)=\mathrm{C}_{\mathrm{v}} \mathrm{Tdm}
$$

and:

$$
\mathrm{dQ}+\left(\mathrm{C}_{\mathrm{p}} \mathrm{T}_{\mathrm{i}} \mathrm{m}_{\mathrm{i}}^{\prime}-\mathrm{C}_{\mathrm{p}} \mathrm{T}_{\mathrm{o}} \mathrm{m}_{\mathrm{o}}^{\prime}\right)=\operatorname{VdP} \frac{\mathrm{C}_{\mathrm{V}}}{\mathrm{R}}
$$

Amount of heat transferred in cooler equals:

$$
\mathrm{dQ}_{\mathrm{k}}=\mathrm{V}_{\mathrm{k}} \frac{\mathrm{C}_{\mathrm{V}}}{\mathrm{R}} \mathrm{dP}-\mathrm{C}_{\mathrm{p}}\left(\mathrm{T}_{\mathrm{ck}} \mathrm{m}_{\mathrm{ck}}^{\prime}-\mathrm{T}_{\mathrm{kr}} \mathrm{m}_{\mathrm{kr}}^{\prime}\right)
$$

and in regenerator:

$$
\mathrm{dQ}_{\mathrm{r}}=\mathrm{V}_{\mathrm{r}} \frac{\mathrm{C}_{\mathrm{V}}}{\mathrm{R}} \mathrm{dP}-\mathrm{C}_{\mathrm{p}}\left(\mathrm{T}_{\mathrm{kr}} \mathrm{m}_{\mathrm{kr}}^{\prime}-\mathrm{T}_{\mathrm{rh}} \mathrm{m}_{\mathrm{rh}}^{\prime}\right)
$$

also in heater:

$$
\mathrm{dQ}_{\mathrm{h}}=\mathrm{V}_{\mathrm{h}} \frac{\mathrm{C}_{\mathrm{V}}}{\mathrm{R}} \mathrm{dP}-\mathrm{C}_{\mathrm{p}}\left(\mathrm{T}_{\mathrm{rh}} \mathrm{m}_{\mathrm{rh}}^{\prime}-\mathrm{T}_{\mathrm{he}} \mathrm{m}_{\mathrm{he}}^{\prime}\right)
$$

The temperature of gas is on the permanent level [3]:

$$
\left\{\begin{array}{l}
\mathrm{T}_{\mathrm{kr}}=\mathrm{T}_{\mathrm{k}} \\
\mathrm{T}_{\mathrm{rh}}=\mathrm{T}_{\mathrm{h}}
\end{array}\right.
$$

Total quantity of work is a sum of a produced work in each cylinder:

$$
\mathrm{W}=\mathrm{W}_{\mathrm{e}}+\mathrm{W}_{\mathrm{c}}
$$

processes are described by adiabatic model hence work of cycle equals:

$$
\mathrm{dW}=\mathrm{pdV}_{\mathrm{e}}+\mathrm{pdV}_{\mathrm{c}}
$$

\subsection{CAFS - Combined Adiabatic-Finite Speed}

Mathematical model developed by Hosseinzadeh and other [7] is an amplification adiabatic model [26], additional elements are mechanical losses and finite speed thermodynamic.

The idea of thermodynamic with finite speed was presented in 50's of 20th century [14]. The assumption of FST is the analysis of real processes which occurred in thermodynamical systems of piston engines towards optimization (increase power and efficiency) and it included irreversible phenomena.

The main task of thermodynamic with finite speed is to describe the interaction between piston (moving with speed $\mathrm{w}_{\mathrm{p}}$ ) and gas molecules located in the system (moving with average speed of sound c).

Petrescu and other [14] demonstrated that in consequence of piston motion gas pressure being over piston surface are different from instantaneous mean pressure in cylinder. This fact means that compression and expansion work are different to calculated work based on the classical thermodynamic. It causes that work generated by engine is 
lower than received work by classical thermodynamic. On account of piston motion local disorder of gas placed in work space is generated leading to make an acoustic wave and as a consequence of this phenomena pressure drops [4]. The propagation of wave took place with the speed of sound [7].

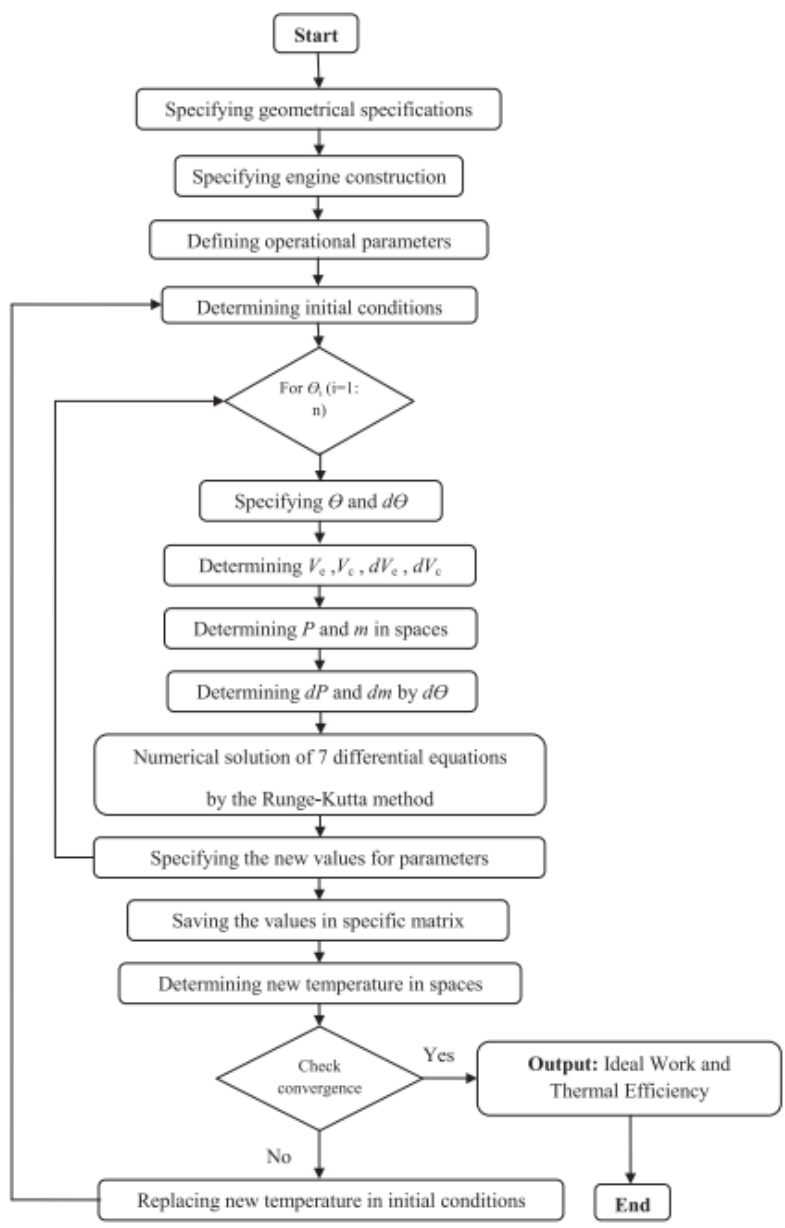

Fig. 13. Flow chart of the algorithm of ideal adiabatic model [7]

The first law of thermodynamics for process with finite speed in a closed system is written as (the scheme of workspace is presented in Fig. 9):

$$
\mathrm{dU}=\delta \mathrm{Q}-\mathrm{p}\left(1 \pm \frac{\mathrm{aw} \mathrm{p}}{\mathrm{c}} \pm \frac{\mathrm{fr} \Delta \mathrm{p}_{\mathrm{f}}}{\mathrm{p}_{\mathrm{m}}}\right) \mathrm{dV}
$$

where $\mathrm{dU}$ is the change of internal energy, $\delta \mathrm{Q}$ is the transferred heat between cylinder and environment, $p$ is the instantaneous mean pressure over piston, $a$ is the coefficient $\mathrm{a}=\sqrt{3 \kappa}[4], \mathrm{w}_{\mathrm{p}}$ is the piston speed, $\mathrm{c}$ is the speed of sound $\mathrm{c}=\sqrt{3 \mathrm{RT}}$ [4]. Friction factor fr is a range of from 0 to 1 . For $\mathrm{fr}=0$ heat transfer took place to environment (compression space), heat is keep in the system while fr $=1$.

One of the assumption is that the present model is adiabatic process during expansion and compression, hence expression $\delta Q=0$. Based on equation (58) work is equal change of internal energy with negative sign:

$$
\mathrm{dU}=-\mathrm{p}\left(1 \pm \frac{\mathrm{aw_{p }}}{\mathrm{c}} \pm \frac{\Delta \mathrm{P}_{\mathrm{f}}}{\mathrm{p}_{\mathrm{m}}}\right) \mathrm{dV}
$$

hence equation (56) is written:

$$
\mathrm{mC}_{\mathrm{v}} \mathrm{dT}=-\mathrm{p}\left(1 \pm \frac{\mathrm{aw}}{\mathrm{c}} \pm \frac{\Delta \mathrm{P}_{\mathrm{f}}}{\mathrm{p}_{\mathrm{m}}}\right) \mathrm{dV}
$$

Work of irreversible process is obtained:

$$
\delta \mathrm{W}_{\mathrm{FST}}=\mathrm{p}\left(1 \pm \frac{\mathrm{aw}}{\mathrm{c}} \pm \frac{\Delta \mathrm{p}_{\mathrm{f}}}{\mathrm{p}_{\mathrm{m}}}\right) \mathrm{dV}
$$

where $\delta \mathrm{W}_{\mathrm{FST}}$ is calculated irreversible work with using FST. Sign (+) is applicated in equations (55)-(58) for describing expansion process, sign $(-)$ occurs while compression process.

Drop pressure $\Delta \mathrm{P}_{\mathrm{f}}$ is caused by mechanical losses (friction) $\Delta \mathrm{P}_{\mathrm{f}}$. it is computed by equation [4]:

$$
\Delta \mathrm{P}_{\mathrm{f}}=\frac{\left(0.4+0.0045 \mathrm{w}_{\mathrm{p}}\right) 10^{5}}{3 \zeta}\left(1-\frac{1}{\mathrm{cr}}\right)
$$

where $\zeta$ is the constant value [5]:

$$
\zeta=1-\frac{1}{\mathrm{cr}}
$$

where $\mathrm{cr}$ is the compression ratio. Total work of engines (with throttle losses) equals [5]:

$$
\delta \mathrm{W}_{\text {total }}=\delta \mathrm{W}_{\mathrm{FST}}+\Delta \mathrm{P}_{\mathrm{th}} \mathrm{dV}
$$

where $\delta \mathrm{W}_{\text {total }}$ is generated work by engine with considered finite piston speed, mechanical friction losses and throttle phenomena in heat exchangers, $\Delta \mathrm{P}_{\text {th }}$ is the drop pressure in heat exchangers, $\mathrm{V}$ is the instantaneous gas volume.

Drop pressure in heater and cooler are significantly lower than in regenerator. According to Darcy-Weisbach drop pressure equals [27]:

$$
\Delta \mathrm{P}=\operatorname{fr} \frac{\mathrm{e}}{2} \frac{\mathrm{L}}{\mathrm{D}_{\mathrm{H}}} \mathrm{u}^{2}
$$

where fr is the friction coefficient, $\varrho$ is the gas density, $\mathrm{L}$ is length, $D_{H}$ is hydraulic diameter and $u$ is the speed of gas flow.

Drop pressure of throttling is obtained in result of summarizing drop pressure in regenerator, cooler and heater:

$$
\Delta \mathrm{P}_{\text {th }}=\Delta \mathrm{P}_{\mathrm{r}}+\Delta \mathrm{P}_{\mathrm{k}}+\Delta \mathrm{P}_{\mathrm{h}}
$$

The efficiency regenerator is calculated based on number of thermal unit (NTU) [7]:

$$
\varepsilon=\frac{\mathrm{NTU}}{1+\mathrm{NTU}}
$$

where $\varepsilon$ is the regenerator efficiency, NTU is the number thermal unit is determined based on formula:

$$
\mathrm{NTU}=\frac{\mathrm{StL}_{\mathrm{r}}}{\mathrm{D}_{\mathrm{hr}}}
$$

where St is Stanton number, $\mathrm{L}_{\mathrm{r}}$ is length of regenerator and $\mathrm{D}_{\mathrm{hr}}$ is regenerator hydraulic diameter. Stanton number is determined based on Reynolds and Prandtl number [13]:

$$
\text { St }=0.023 \mathrm{Re}^{-0.2} \mathrm{Pr}^{-0.6}
$$

Hydraulic diameter is calculated in the following way [7]:

$$
\mathrm{D}_{\mathrm{hr}}=\frac{4 \Pi}{\Phi(1-\Pi)}
$$

where $\Pi$ is the porosity regenerator, $\Phi$ is the coefficient shape is related with volumen and surface:

$$
\Phi=\frac{A_{\mathrm{wg}}}{\mathrm{V}_{\mathrm{mr}}}
$$


where $A_{w g}$ is the wetted surface and $V_{m r}$ is the volume of wires regenerator. Gas temperature in heater and cooler is received by solving equations [7]:

$$
\begin{aligned}
& T_{h}=T_{w h}-\frac{f r\left[Q_{h}+Q_{r}\left(1-\varepsilon_{r}\right)\right]}{\alpha_{h} A_{h}} \\
& T_{k}=T_{w k}-\frac{f r\left[Q_{k}+Q_{r}\left(1-\varepsilon_{r}\right)\right]}{\alpha_{k} A_{k}}
\end{aligned}
$$

where $T_{h}$ is the gas temperature in heater, $T_{w h}$ is the wall temperature in heater, fr is engine frequency, $Q_{h}$ is heat supplied to the heater, $\mathrm{Q}_{\mathrm{r}}$ is heat exchanged in regenerator, $\varepsilon_{\mathrm{r}}$ is regenerator efficiency, $\alpha_{\mathrm{h}}$ is heat transfer coefficient in heater, $A_{h}$ is heat transfer surface in heater, $T_{k}$ is gas temperature in heater, $Q_{k}$ is heat removed from the cooler, $\alpha_{k}$ is the heat transfer coefficient in cooler and $A_{k}$ is the heat transfer surface in cooler. Heat transfer coefficient is obtained using the following equation [7]:

$$
\alpha=\frac{0.0791 \mu \mathrm{C}_{\mathrm{p}} \mathrm{Re}^{0.75}}{2 \mathrm{D}_{\mathrm{h}} \operatorname{Pr}}
$$

where $\alpha$ is heat transfer coefficient, $\mu$ is dynamic viscosity, $\mathrm{C}_{\mathrm{p}}$ is the specific heat and $\mathrm{D}_{\mathrm{h}}$ is hydraulic diameter.

\subsection{PSVL - Polytropic model Stirling with various losses}

Babaelahi and other [1] developed their model based on the adiabatic model. Energy balance according to first law of thermodynamic for open system is as follows [1]:

$$
\begin{aligned}
\mathrm{dQ}-\mathrm{d} Q_{\text {poli }}-\mathrm{dQ} Q_{\text {sh }}+ & \left(\mathrm{m}_{\mathrm{i}} \mathrm{C}_{\mathrm{p}, \mathrm{i}} \mathrm{T}_{\mathrm{i}}-\mathrm{m}_{\mathrm{o}} \mathrm{C}_{\mathrm{p}, \mathrm{o}} \mathrm{T}_{\mathrm{o}}\right)= \\
= & \mathrm{dW}+\mathrm{C}_{\mathrm{V}} \mathrm{d}(\mathrm{mT})
\end{aligned}
$$

where dQ is transferred heat between working gas and environment, $\mathrm{dW}$ is network generated by engine, $\mathrm{dQ}_{\text {poli }}$ is heat emitted in compression and expansion space by polytropic model and $\mathrm{dQ}_{\mathrm{sh}}$ is transferred heat by displacer from expansion to compression space shuttle effect of piston [1]:

$$
\mathrm{dQ}_{\mathrm{sh}}=\frac{\pi \mathrm{S}^{2} \lambda_{\mathrm{t}} \mathrm{D}_{\mathrm{dis}}\left(\mathrm{T}_{\mathrm{e}}-\mathrm{T}_{\mathrm{c}}\right)}{8 \mathrm{~J} \mathrm{~L}_{\mathrm{dis}}}
$$

where $S$ is stroke, $\lambda_{\text {dis }}$ is the displacer thermal conductivity $D_{\text {dis }}$ is diameter of displacer, $J$ is size of the gap between the displacer and the cylinder, $\mathrm{L}_{\mathrm{dis}}$ is length of displacer. The fourth piece of left side equation (73) is related with enthalpy change of the working substance. The second piece of right side energy balance equation concerns change of internal energy in volume. Transferred heat into environment $\mathrm{dQ}_{\text {poli }}$ in compression and expansion chamber is obtained [8]:

$$
\mathrm{Q}_{\text {poli }}=\mathrm{mC}_{\mathrm{n}}\left(\mathrm{T}_{0}-\mathrm{T}\right)
$$

where $C_{n}$ is the specific heat polytropic, $T_{0}$ is the ambient temperature and $\mathrm{T}$ is the temperature in controlled space. Differential form of equation energy balance is written as:

$$
\mathrm{dQ}_{\text {poli }}=\mathrm{C}_{\mathrm{n}}\left(\mathrm{T}_{0}-\mathrm{T}\right) \mathrm{dm}-\mathrm{mC}_{\mathrm{n}} \mathrm{dT}
$$

Polytropic specific heat is determined in the following way [17]:

$$
\mathrm{C}_{\mathrm{n}}=\mathrm{C}_{\mathrm{V}} \frac{\mathrm{n}-\mathrm{k}}{\mathrm{n}-1}
$$

According to the polytropic equation:

$$
\mathrm{PV}^{\mathrm{n}}=\text { const }
$$

whereas differential form of polytropic equation equals:

$$
P\left(n V^{n-1} d V\right)+n V^{n} d P=0
$$

hence polytropic exponent:

$$
n=-\frac{V d P}{P d V}
$$

After modification we get a formula describing the change of mass gas:

$$
\mathrm{dm}_{\mathrm{c}}=\frac{\left[\left(\frac{\mathrm{PdV}_{\mathrm{c}}+\frac{\mathrm{V}_{\mathrm{c}}}{\mathrm{KT}} \mathrm{dP}}{\mathrm{RT}}\right)-\left(\frac{\mathrm{C}_{\mathrm{nc}} \mathrm{m}_{\mathrm{c}}}{\mathrm{C}_{\mathrm{p}} \mathrm{T}_{\mathrm{ck}}} \mathrm{dT}_{\mathrm{c}}\right)-\left(\frac{\mathrm{Q}_{\mathrm{sh}}}{\mathrm{C}_{\mathrm{p}} \mathrm{ck}}\right)\right]}{\left[\left(\frac{\mathrm{Cnc}_{\mathrm{nc}}}{\mathrm{C}_{\mathrm{p}}}\right)\left(\frac{\mathrm{T}_{0}-\mathrm{T}_{\mathrm{c}}}{\mathrm{T}_{\mathrm{ck}}}\right)+1\right]}
$$

where $\mathrm{C}_{\mathrm{nc}}$ is the polytropic exponent in compression space and $\mathrm{C}_{\mathrm{ne}}$ is the polytropic exponent in expansion space, thus $\mathrm{dm}_{\mathrm{c}}=\dot{\mathrm{m}}_{\mathrm{ck}}$. An analogous description is retained for the expansion space

$$
\mathrm{dm}_{\mathrm{e}}=\frac{\left[\left(\frac{\mathrm{PdV}_{\mathrm{e}}+\frac{\mathrm{V}_{\mathrm{e}}}{\mathrm{K}} \mathrm{dP}}{\mathrm{RT}_{\mathrm{he}}}\right)-\left(\frac{\mathrm{C}_{\mathrm{ne}} \mathrm{m}_{\mathrm{e}}}{\mathrm{C}_{\mathrm{p} \mathrm{T}} \mathrm{T}_{\mathrm{ck}}}\right)-\left(\frac{\mathrm{Q}_{\mathrm{sh}}}{\mathrm{C}_{\mathrm{pT}} \mathrm{T}_{\mathrm{he}}}\right)\right]}{\left[\left(\frac{\mathrm{C}_{\mathrm{ne}}}{\mathrm{C}_{\mathrm{p}}}\right)\left(\frac{\mathrm{T}_{0}-\mathrm{T}_{\mathrm{e}}}{\mathrm{T}_{\mathrm{he}}}\right)+1\right]}
$$

By ordering the expressions (80) and (81), the equation defining the change in pressure $\mathrm{dP}$ is obtained:

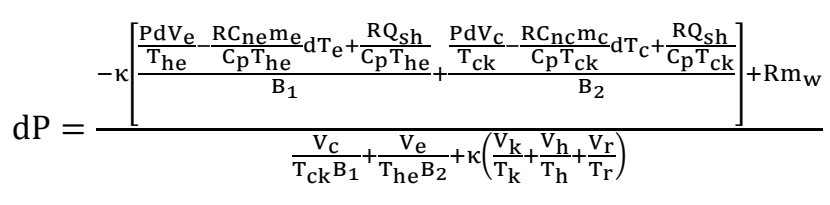

where:

$$
\begin{aligned}
& \mathrm{B}_{1}=\left(\frac{\mathrm{C}_{\mathrm{nc}}}{\mathrm{C}_{\mathrm{p}}}\right)\left(\frac{\mathrm{T}_{0}-\mathrm{T}_{\mathrm{c}}}{\mathrm{T}_{\mathrm{ck}}}\right)+1 \\
& \mathrm{~B}_{2}=\left(\frac{\mathrm{C}_{\mathrm{ne}}}{\mathrm{C}_{\mathrm{p}}}\right)\left(\frac{\mathrm{T}_{0}-\mathrm{T}_{\mathrm{e}}}{\mathrm{T}_{\mathrm{he}}}\right)+1
\end{aligned}
$$

Working gas temperature in compression space is calculated based on following expression:

$$
\mathrm{dT}_{\mathrm{c}}=\mathrm{T}_{\mathrm{c}}\left(\frac{\mathrm{dP}}{\mathrm{p}}+\frac{\mathrm{dV}_{\mathrm{c}}}{\mathrm{V}_{\mathrm{c}}}-\frac{\mathrm{dm}_{\mathrm{c}}}{\mathrm{m}_{\mathrm{c}}}\right)
$$

Gas temperature in expansion space is computed in a similar way:

$$
\mathrm{dT}_{\mathrm{e}}=\mathrm{T}_{\mathrm{e}}\left(\frac{\mathrm{dP}}{\mathrm{p}}+\frac{\mathrm{dV}_{\mathrm{e}}}{\mathrm{V}_{\mathrm{c}}}-\frac{\mathrm{dm}_{\mathrm{e}}}{\mathrm{m}_{\mathrm{e}}}\right)
$$

Transferred heat into the heat exchanger equals respectively [9]:

$$
\begin{aligned}
& \mathrm{dQ}_{\mathrm{k}}=\mathrm{V}_{\mathrm{k}} \frac{\mathrm{C}_{\mathrm{V}}}{\mathrm{R}} \mathrm{dP}-\mathrm{C}_{\mathrm{p}}\left(\mathrm{T}_{\mathrm{ck}} \dot{\mathrm{m}}_{\mathrm{ck}}-\mathrm{T}_{\mathrm{kr}} \dot{\mathrm{m}}_{\mathrm{kr}}\right) \\
& \mathrm{dQ}_{\mathrm{h}}=\mathrm{V}_{\mathrm{h}} \frac{\mathrm{C}_{\mathrm{V}}}{\mathrm{R}} \mathrm{dP}-\mathrm{C}_{\mathrm{p}}\left(\mathrm{T}_{\mathrm{rh}} \dot{\mathrm{m}}_{\mathrm{rh}}-\mathrm{T}_{\mathrm{he}} \dot{\mathrm{m}}_{\mathrm{he}}\right) \\
& \mathrm{dQ} \mathrm{Q}_{\mathrm{r}}=\mathrm{V}_{\mathrm{r}} \frac{\mathrm{C}_{\mathrm{V}}}{\mathrm{R}} \mathrm{dP}-\mathrm{C}_{\mathrm{p}}\left(\mathrm{T}_{\mathrm{kr}} \dot{\mathrm{m}}_{\mathrm{kr}}-\mathrm{T}_{\mathrm{rh}} \dot{\mathrm{m}}_{\mathrm{rh}}\right)
\end{aligned}
$$

Generated work by gas in compression space:

$$
\mathrm{dW}_{\mathrm{c}}=\mathrm{pdV}_{\mathrm{c}}
$$

and expansion space:

$$
\mathrm{dW}_{\mathrm{e}}=\mathrm{pdV}_{\mathrm{e}}
$$

Overall work was produced by engine is a sum of work made by gas in compression and expansion space.

$$
\mathrm{W}=\int \mathrm{dW}_{\mathrm{c}}+\int \mathrm{d} \mathrm{W}_{\mathrm{e}}
$$


Engine efficiency is quotient of work engines (92) and delivered heat into system (88):

$$
\eta_{\text {netto }}=\frac{\mathrm{w}}{\mathrm{Q}_{\mathrm{h}}}
$$

The assumption of nonideal heat transfer in regenerator means that efficiency is lower than 100 percent. Regenerator efficiency $\varepsilon$ is defined as its ability to change gas enthalpy that is a real change of enthalpy to the theoretical maximum change of gas enthalpy. Included heat loss, amount of heat delivered to the heater and taking from cooler equals:

$$
\begin{aligned}
& Q_{\mathrm{h}}=\mathrm{Q}_{\text {hid }}+\mathrm{Q}_{\mathrm{rl}}=\mathrm{Q}_{\text {hid }}+\mathrm{Q}_{\text {rid }}(1-\varepsilon) \\
& \mathrm{Q}_{\mathrm{k}}=\mathrm{Q}_{\text {kid }}-\mathrm{Q}_{\mathrm{rl}}=\mathrm{Q}_{\text {kid }}-\mathrm{Q}_{\text {rid }}(1-\varepsilon)
\end{aligned}
$$

Element $Q_{\text {rid }}(1-\varepsilon)$ represents heat loss in the regenerator. In comparison with formulas (94)-(95) in this analyze it is regarded regenerator efficiency $\varepsilon$. Regenerator efficiency with assumption linear profile of temperature [26] as function inlet and outlet temperature [1]:

$$
\varepsilon=\frac{1}{1+\frac{\delta \mathrm{T}}{\mathrm{T}_{\mathrm{h}_{\mathrm{i}}}-\mathrm{T}_{\mathrm{h}_{\mathrm{o}}}}}
$$

where $\varepsilon$ is the regenerator efficiency, $\delta \mathrm{T}$ is the difference temperature between flowing gas from heater in regenerator and flowing gas from cooler, $\mathrm{T}_{\mathrm{h}_{\mathrm{i}}}$ is the inlet gas temperature to regenerator from heater and $\mathrm{T}_{\mathrm{h}_{\mathrm{o}}}$ is the outlet gas temperature from regenerator. According to the equation (96) the increase of regenerator efficiency occurs when outlet gas temperature $\mathrm{T}_{\mathrm{h}_{\mathrm{o}}}$ reaches lower temperature (supplying regenerator from heater side - in regenerator more heat is located). Heat balance of the flowing gas equals $\dot{m C}_{\mathrm{p}}\left(\mathrm{T}_{\mathrm{h}_{\mathrm{i}}}\right.$ $\left.+\mathrm{T}_{\mathrm{h}_{\mathrm{o}}}\right)=\alpha \mathrm{A}_{\mathrm{wg}} \delta \mathrm{T}$. In consequence regenerator efficiency is defined as:

$$
\varepsilon=\frac{1}{1+\frac{\dot{m}_{p}}{\alpha A_{w g}}}=\frac{1}{1+\frac{1}{\mathrm{NTU}}}=\frac{\mathrm{NTU}}{1+\mathrm{NTU}}
$$

where $\dot{m}$ is the mass flow rate, $C_{p}$ is the specific heat of gas, $\alpha$ is heat transfer coefficient, $A_{w g}$ is the wetted surface by gas.

It is impossible to implement the isothermal model in reality. Hence this model might be only used in order to determine maximum efficiency for the examined engine. This model is based on algebraic equation, this fact allows calculation in an easy way. In other words, results of the isothermal model is upper limit in regarding reached values of the power and efficiency.

Adiabatic model is closer to real engines than isothermal one because in expansion and compression space temperature change occurs but in the heat changers there is still a constant temperature. In the real engines heat transfer appears mainly in the heat exchanger, in significantly small scale in cylinder, so this model is discrepant from real conditions. Adiabatic model is basic for modern models.

In Combined Adiabatic model with Finite Speed an assumption is included that the change of temperature in heat exchangers, nonideal regenerator and mechanical (friction) losses, pressure losses (throttling) and thermodynamics with finite speed. Polytropic model is development of this approach.

One of serious restriction for CAFS and PVSL is necessary awareness of exact specification. Full technical specification often is restricted by producers. CAFS and PVSL (and other models with nonisothermal processes in heat exchangers and cylinders) might be used for modelling real machines.

Isothermal and simple adiabatic model might be only applicable for tentative calculations - estimating power and efficiency for set parameters.

\section{Conclusions}

So far devices with Stirling engines offered nowadays on market are mostly not designed to supply with lowtemperature heat sources, usually they are equipped with a combustion chamber allowing supply with conventional fuels such as compressed natural gas or mixture of propane and butane. Heaters of such kind of engines c cannot be directly used to supply with contaminated flue gas due to the small cross-sectional area of slots, which the gas passes.

Few examples of devices that enable the use of waste energy, require proper operation of the temperature of energy source no lower than $500^{\circ} \mathrm{C}$. Such restrictions have two main reasons: the first one, of a technical nature, heavy mechanical losses in the SE caused by high pressure of working gas, often exceeding $60 \mathrm{MPa}$ [29]. The second reason is of economical nature, SE supplied with low temperature heat source will have extremely long period of return on investment (» 20 years).

The key improvements, which must be done before commercialization of SE supplied with low temperature renewable sources are lowering the mechanical losses in the SE, rising performance of the flue gases - working gas heat exchanger and developing low cost manufacturing technology that ensures low cost of production.

The analysed numerical models of SE operation have a different level of complexity and describe the processes taking place in a real device with a different degree of idealization. Depending on the stage of development of structures powered by low-temperature energy sources, the presented models can be effectively used to determine the direction of changes in the design parameters of the device. The first of them the isothermal model (section 3.1) enables the analysis of the main design parameters of the device without the necessity to take into account the empirical coefficients that are difficult to collect at the initial design stage of design. In engines powered by low-temperature energy sources, it is extremely difficult to design a structure, in which the heat is delivered in the expansion space and not through an external heat exchanger. Hence, the adiabatic model (section 3.2) will be characterized by a higher accuracy, but still does not require the use of hardto-obtain empirical coefficients. This kind of model is unfortunately more computationally demanding. The next CAFS model - Combined Adiabatic-Finite Speed (section 3.3) should be applied, when the structural details of the designed device are known, the computational base is the adiabatic model, however, a number of hydraulic losses are also taken into account. Experimental coefficients are required for the calculations. The last model, with the most 
complexity, PSVL - Polytropic model Stirling with various losses (section 3.4), enables a more detailed description of the phenomena occurring in the area of compression and expansion by using a polytropic model instead of the adia- batic one. It takes into account a similar model of hydraulic losses as previously described, and at the same time requires the greatest number of experimental factors.

\section{Nomenclature}

CAFS Combined Adiabatic Finite Speed

FST Finite Speed Thermodynamics

NTU Number of transfer units
PSVL Polytropic model Stirling with Various Losses SE Stirling Engine

\section{Bibliography}

[1] BABAELAHI, M., SAYYAADI, H. A new thermal model based on polytropic numerical simulation of Stirling engines. Applied Energy. 2015, 141, 143-159.

https://doi.org/10.1016/j.apenergy.2014.12.033

[2] BABAELAHI, M., SAYYAADI, H. Modified PSVL: A second order model for thermal simulation of Stirling engines based on convective-polytropic heat transfer of working spaces. Applied Thermal Engineering. 2020, 85, 340355. https://doi.org/10.1016/j.applthermaleng.2015.03.018

[3] CHEN, N.C.J., GRIFFIN, F.P. Review of Stirling-engine mathematical models. Oak Ridge, TN 1993. https://doi.org/10.2172/5948203

[4] COSTEA, M., PETRESCU, S., HARMAN, C. Effect of irreversibilities on solar Stirling engine cycle performance. Energy Conversion and Management. 1999, 40(15), 17231731. https://doi.org/10.1016/S0196-8904(99)00065-5

[5] Engines, Microgen.

https://www.microgen-engine.com/engines/

[6] GARCÍA, M.T., TRUJILLO, E.C., GODIÑO, J.A.V. et al. Thermodynamic model for performance analysis of a Stirling engine prototype. Energies. 2018, 11(10). https://doi.org/10.3390/en11102655

[7] HOSSEINZADE, H., SAYYAADI, H. CAFS: The combined adiabatic-finite speed thermal model for simulation and optimization of Stirling engines. Energy Conversion and Management. 2014, 91, 32-53.

https://doi.org/10.1016/j.enconman.2014.11.049

[8] Inspirit Charger https://www.inspirit-energy.com/the-inspirit-charger/

[9] INVERNIZZI, C.M. Closed power cycles: Thermodynamic fundamentals and applications. Lecture Notes in Energy. 2013, 11. https://doi.org/10.1007/978-1-4471-5140-1

[10] KROPIWNICKI, J. Analysis of start energy of Stirling engine type alpha. Archives of Thermodynamics. 2019, 40(3), 243-259. https://doi.org/10.24425/ather.2019.130004

[11] ML3000, Genoa Stirling. https://genoastirling.com/eng/engine-ml3000.php

[12] ML1000, Genoa Stirling. https://genoastirling.com/eng/engine-ml1000.php

[13] ORGAN, A.J. The Regenerator and the Stirling Engine. Wiley-Blackwel. 1997.

[14] PETRESCU, S., COSTEA, M., FEIDT, M. et al. Advanced thermodynamics of irreversible processes with finite speed

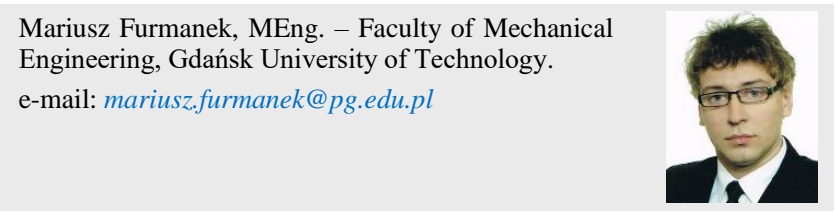

and finite dimension. AGIR Publishing House Bucharest 2015, 259-273.

[15] PowerGen 1200, Protek Safety \& Control.

https://www.proteksc.com/pdf/PowerGen-1200.pdf

[16] PowerGen 5650, Protek Safety \& Control. https://www.proteksc.com/pdf/PowerGen-1200.pdf

[17] PUDLIK, W. Termodynamika. Gdansk University of Technology Publishing House. Gdańsk 2011.

[18] SCHMIDT, G. Classical analysis of operation of Stirling engine. 1871, 15. A report published in German engineering union.

[19] STANDARD ENGINE CATALOG, Genoa Stirling. https://genoastirling.com/attach/Catalogo_2017_ENG.pdf

[20] Stirling generators, Sunnytek. http://www.sunnytek.se/solenergi/termoelektriskenergiteknik/stirling-generators.pdf

[21] URIELI, I. Chapter 3a - Ideal Isothermal Analysis. https://www.ohio.edu/mechanical/stirling/isothermal/isother mal.html

[22] URIELI, I. Chapter 4a - Ideal Adiabatic Analysis. https://www.ohio.edu/mechanical/stirling/adiabatic/adiabatic .html

[23] URIELI, I. Energy analysis - ideal isothermal model. www.ohio.edu/mechanical/stirling/isothermal/energy.html

[24] URIELI, I. Regenerator mean effective temperature. https://www.ohio.edu/mechanical/stirling/isothermal/regenT .html

[25] URIELI, I. Stirling engine ideal adiabatic analysis (updated $1 / 15 / 10)$.

https://www.ohio.edu/mechanical/stirling/adiabatic/adiabatic .html

[26] URIELI, I., BERCHOWITZ, D. Stirling Cycle Engine Analysis. Hingham: Adam Hilger Ltd. 1994.

[27] WAJS, J., MIKIELEWICZ, D., JAKUBOWSKA, B. Performance of the domestic micro ORC equipped with the shell-and-tube condenser with minichannels. Energy. 2018, 157, 853-861. https://doi.org/10.1016/j.energy.2018.05.174

[28] Whispergen PPS 16. https://www.victronenergy.com/Manuals/WhisperGen/User Manual/UserBookDO40015D.pdf

[29] WU, C., CHEN, L., CHEN, J. Recent advances in finitetime thermodynamics. Nova Science Publishers. 1999.

Jacek Kropiwnicki, DSc., DEng. - Faculty of Mechanical Engineering, Gdańsk University of Technology.

e-mail: jkropiwn@pg.gda.pl 